\title{
Determinação da variabilidade espacial de alumínio em função da distribuição de argila em solos de Querência do Norte/Paraná, Brasil
}

\section{Determination of spatial variability of aluminum according to the clay distribution in soils of Querência do Norte/Paraná State, Brazil}

\author{
Marcelo Luiz Chicati ${ }^{1 *}$; Marcos Rafael Nanni²; Everson Cézar ${ }^{3}$
}

\begin{abstract}
Resumo
A maior parte dos solos brasileiros possui altos teores de alumínio e, em muitos casos, este elemento ocorre em níveis fitotóxicos. Constituinte dos minerais de argila, pode ter sua liberação diretamente na forma trocável ou para a solução do solo. O objetivo deste trabalho foi demonstrar a relação entre a variabilidade espacial do alumínio e a distribuição de argila do solo. Para isto, foi coletada uma malha de amostras de solo em campo, definida por meio de fotointerpretação e observação de imagens. Os resultados obtidos em laboratório foram submetidos a análises estatísticas visando a verificação da dependência espacial, que foi comprovada posteriormente. A continuidade espacial foi estudada mediante a elaboração de semivariogramas utilizando-se diferentes modelos. Os melhores semivariogramas foram escolhidos mediante a validação cruzada executada por meio de "krigagem" ordinária. Dessa forma, pôde-se observar que as variáveis estudadas apresentaram estrutura de dependência espacial, com correlação positiva entre si. Esses resultados possibilitaram a geração de mapas capazes de auxiliar o melhor aproveitamento agrícola da área.

Palavras-chave: Geoestatística, semivariogramas, "Krigagem" ordinária
\end{abstract}

\begin{abstract}
The major part of Brazilian soils shows elevated aluminum contents and in several cases this element occurs in phytotoxic levels. Aluminum is a constituent of the soil's clay minerals. Its release can occur to the exchangeable fraction or to the soil solution. The objective of this work was to demonstrate the relationship between the spatial variability of aluminum and the distribution of soil clay. In order to achieve that, a grid of soil samples was collected in field, defined by means of photointerpretation and observation of images. The results obtained in laboratory were submitted to statistical analyses to verify spatial dependence, which was proven later. The space continuity was studied by means of the semivariogram's elaboration using different models. The best semivariograms were chosen by cross validation performed through "ordinary kriging". Thus, it could be observed that these variables showed structure of spatial dependence, with a positive correlation between them, besides it was possible to make maps in order to allow a better agricultural exploitation.
\end{abstract}

Key words: Geostatistics, semivariograms, ordinary kriging

1 Prof. Dr. Dept ${ }^{\circ}$ de Engenharia Civil, Centro de Tecnologia, Universidade Estadual de Maringá, UEM, Maringá, PR. E-mail: mlchicati@hotmail.com

2 Prof. Dr. Dept ${ }^{\circ}$ de Agronomia. Centro de Ciências Agrárias. Universidade Estadual de Maringá, UEM, Maringá, PR. E-mail: mrnanni@uem.br

3 Doutorando do Dept ${ }^{\circ}$ de Agronomia. Centro de Ciências Agrárias, Universidade Estadual de Maringá, UEM, Maringá, PR. E-mail: eversoncezar@yahoo.com.br

* Autor para correspondência

Recebido para publicação 22/04/2010 Aprovado em 19/08/2011 


\section{Introdução}

A produtividade de uma área agrícola é afetada, dentre outros fatores, pelas propriedades químicas de seus solos. Sendo assim, a maioria dos solos brasileiros deve ser manejada quimicamente, pois apresenta teores de alumínio em níveis tóxicos para as plantas. Além disso, geralmente os teores de cálcio e magnésio trocáveis são baixos, características desfavoráveis ao desenvolvimento da maioria das culturas (SOUSA; LOBATO, 2004), pois causam desordens fisiológicas provocadas pela indisponibilidade ou desbalanço entre nutrientes (BARBER, 1995).

O alumínio é constituinte das partículas de argila do solo, ocorrendo a sua liberação para a fração trocável ou para a solução do solo, em situações onde o pH apresenta-se abaixo de 5,0 (FOY et al., 1965). A calagem corrige apenas as camadas superficiais do solo podendo o subsolo permanecer ainda ácido. Neste caso, o crescimento das raízes pode ficar restrito às camadas superficiais do solo, principalmente nas cultivares sensíveis ao alumínio.

A toxicidade do alumínio é uma das maiores limitações para a produção de culturas. À medida que o $\mathrm{pH}$ diminui, aumenta a atividade do alumínio na solução do solo e, conseqüentemente, ocorre a potencialização dos efeitos nocivos e deletérios desse elemento às culturas (SALET; ANGHINONO; KOCHHANN, 1999). Para se compreender melhor esses efeitos, é necessário conhecer e quantificar a variação das propriedades químicas dos solos, tanto horizontal como verticalmente. Isso ocorre pelo fato dos solos serem sistemas dinâmicos e abertos, estando em constante modificação, constituindo assim corpos heterogêneos.

As variações espaciais podem ser avaliadas por meio de técnicas estatísticas descritivas, que não levam em consideração a estrutura espacial existente nos solos amostrados, mas também podem ser avaliadas por técnicas geoestatísticas, que verificam a relação entre as várias amostras de uma mesma área, usando-se o estudo de variáveis regionalizadas e sazonadas. A avaliação das características dos solos por essa metodologia torna possível a obtenção de dados mais acurados (PANOSSO et al., 2009).

Vários autores já demonstraram por meio de técnicas geoestatísticas que a variabilidade do solo não é puramente aleatória, mas apresentam correlação ou dependência espacial (VIEIRA; NIELSEN; BIGGAR, 1981; VIEIRA et al., 1983; TRANGMAR; YOST; UEHARA, 1985, SALVIANO; VIEIRA; SPAROVEK, 1998; SOUZA; COGO; VIEIRA, 1999; OLIVEIRA et al., 1999; BERG; OLIVEIRA, 2000). Segundo Trangmar, Yost e Uehara (1985), Fietz (1998) e Gonçalves (1997), a estatística clássica assume que a variabilidade do valor de uma propriedade do solo em torno da média é aleatória e independente da posição espacial dos valores amostrais. No entanto, Vieira, Nielsen e Biggar (1981) mostraram que a variabilidade de propriedades do solo é espacialmente dependente. Ou seja, dentro de certo domínio, as diferenças entre os valores de uma propriedade do solo podem ser expressas em função da distância de separação entre as observações medidas.

Esse trabalho teve por objetivo demonstrar a relação entre a variabilidade espacial do alumínio e a distribuição espacial de argila no solo, para, desta forma, indicar a possibilidade de dependência espacial entre variáveis devidamente regionalizadas.

\section{Material e Métodos}

A área de estudo situa-se no município de Querência do Norte, mais precisamente na porção paranaense da Área de Proteção Ambiental (APA) das Ilhas e Várzeas do Rio Paraná. Nesta APA, foi delimitada uma área piloto localizada pelas coordenadas UTM, no fuso $22 \mathrm{SW} 7428-7438 \mathrm{~km}$ e 238 - $252 \mathrm{~km}$ do Equador, com área total de 7014 ha.

A malha de pontos de coleta de amostras em campo, também chamada Grade de Amostragem, 
foi definida por meio de fotointerpretação, com definição das unidades fisiográficas da área de estudo e também a observação das imagens orbitais coletadas pelo sensor Thematic Mapper do satélite Landsat 5 disponíveis para melhor caracterização do uso das terras (EMBRAPA, 1996).

Em análise prévia, foram determinados os compartimentos fisiográficos da região e suas características visuais foram obtidas por meio das imagens orbitais devidamente tratadas. A partir daí, admitiu-se a necessidade de coleta de 77 pontos em campo para representar as porções mais significativas do terreno, sendo estes pontos espaçados entre si com eqüidistância de 500 metros para que se obtivesse a cobertura de variações como classes de solo, relevo e cobertura vegetal (Figura $1)$.

Figura 1. Carta de localização da área de estudos contendo o grid de amostragem de solos.

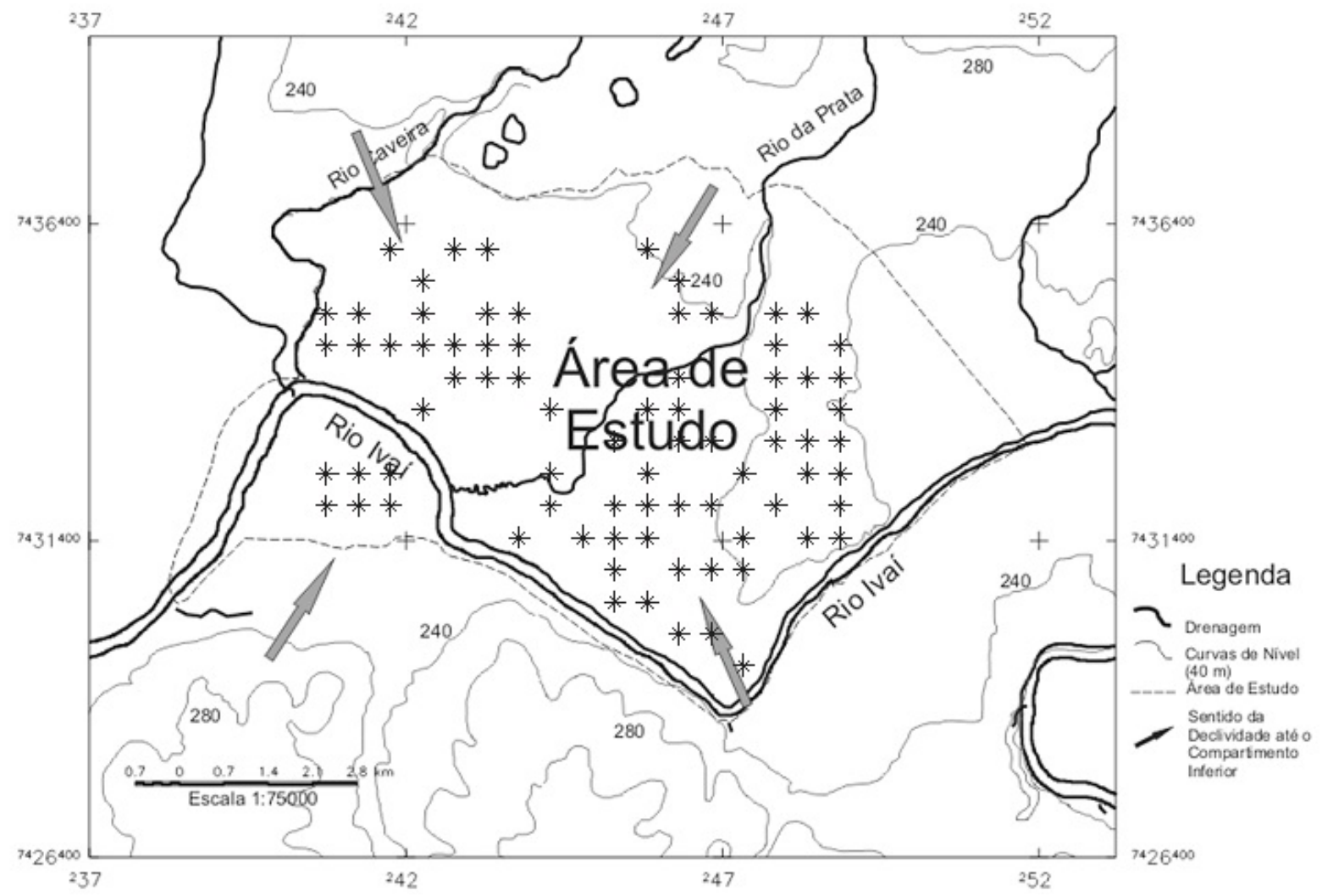

Para a execução dos trabalhos cartográficos e elaboração da grade de amostragem, utilizou-se o Sistema de Informações Geográficas SPRING (INPE, 2004) por meio da confecção de um banco de dados georreferenciados. Esse banco de dados pôde ser trabalhado com diversos algoritmos deste software que tem a capacidade de auxiliar o processamento para tal fim. O sistema SPRING de geoprocessamento é do tipo orientado-a-objeto, com múltiplas funções e algoritmos para processamento de bancos de dados georreferenciados (CÂMARA; MEDEIROS, 1998).

Após a definição da grade de amostragem, foi realizada a coleta dos dados em campo com a utilização de Sistema de Posicionamento Global (GPS), receptor modelo Geoexplorer 3 com modo de 
correção diferencial, possibilitando posicionamento com erro menor do que 5 metros. Em cada ponto localizado foram coletadas amostras dos horizontes superficial $(0-0,20 \mathrm{~m})$ e subsuperficial $(0,80-1,00$ m) dos solos, em camadas variadas, de acordo com a característica observada em cada ponto.

As amostras foram coletadas com trado tipo Holandês e acondicionadas em sacos plásticos de 5 litros, permanecendo fechados até chegada ao laboratório. Cada amostra foi seca ao ar e passada em peneira de $2 \mathrm{~mm}$ (TFSA).

Para a determinação dos teores de areia total, silte e argila, foi utilizado o método do densímetro (EMBRAPA, 1997). Os grupamentos texturais dos solos foram definidos conforme Embrapa (2006). Acidez ativa e de reserva $\left(\mathrm{H}^{+}+\mathrm{Al}^{+3}\right)$ determinadas por titulometria $\left(\mathrm{KCl} 1\right.$ mol. $\mathrm{L}^{-1}+\mathrm{NaOH} 0,025$ mol. $\left.\mathrm{L}^{-1}\right), \mathrm{pH}$ e bases trocáveis $\left(\mathrm{K}^{+}\right.$em Mehlich 1; $\mathrm{Ca}^{+2}$ e $\mathrm{Mg}^{+2}$ por espectrofotometria de absorção atômica) foram determinados segundo Embrapa (1997). A capacidade de troca de cátions (CTC) foi determinada pela adição: soma de bases trocáveis $\left(\mathrm{SB}=\mathrm{K}^{+}, \mathrm{Ca}^{+2}, \mathrm{Mg}^{+2}\right)+\left(\mathrm{H}^{+}+\mathrm{Al}^{+3}\right)$. A saturação por bases $(\mathrm{V} \%)$ foi calculada como (SB/CTC)*100 e a saturação de alumínio $(\mathrm{m} \%)$ como $\left(\mathrm{Al}^{+3} / \mathrm{SB}\right) * 100$, conforme Embrapa (1997).

Depois de obtidos os dados de porcentagem de argila e teor de alumínio, os mesmos foram submetidos a análises estatísticas, tanto descritivas como exploratórias, visando a verificação da dependência espacial, além da interpolação dos mesmos por meio de "krigagem".

O estudo das variáveis a partir dos dados originais foi realizado por meio do software estatístico STATISTICA 6.0 (STATSOFT, 1996), e com este foi realizado o teste de distribuição de normalidade (Shapiro-Wilk). A partir deste procedimento foi possível conhecer a distribuição espacial dos dados na área e sua tendência quanto à existência de variabilidade espacial. O refinamento dos dados foi realizado na seqüência visando a identificação de valores discrepantes (LIBARDI et al., 1996) e possíveis correções quanto a problemas de tendência.

Ao assumir a estacionaridade intrínseca, a continuidade espacial foi analisada mediante a elaboração de semivariogramas (MCBRATNEY; WEBSTER, 1986). A função de semivariância foi calculada pela seguinte equação:

$$
\gamma(h)=(1 / 2 N(h)) \Sigma_{i=1}^{N(h)}\left[Z\left(s_{i}\right)-Z\left(s_{i}+h\right)\right]^{2}
$$

onde, $\mathrm{N}(\mathrm{h})$ : número de pares de valores medidos $\mathrm{Z}\left(\mathrm{s}_{\mathrm{i}}\right), \mathrm{Z}\left(\mathrm{s}_{\mathrm{i}}+\mathrm{h}\right)$ separados pelo vetor $\mathrm{h}$.

Por se tratar de um estudo que envolve variabilidade espacial, esperou-se um valor baixo como início do semivariograma, denominado "nugget effect - efeito pepita" $\left(\mathrm{C}_{0}\right)$ que permanecesse crescente até um valor máximo denominado alcance, que representa também o limite da dependência espacial. Para cada variável distinta foram construídos os semivariogramas utilizando-se os modelos esférico, exponencial e gaussiano com auxílio do software Variowin (PANNATIER, 1996). Os melhores semivariogramas foram escolhidos mediante a validação cruzada executada por meio de "krigagem" ordinária para obtenção de $\mathrm{Z}^{*}\left(\mathrm{x}_{\mathrm{i}}\right)$, além da modelagem de mapas tridimensionais obtidos com o uso do software Surfer (GOLDEN SOFTWARE, 2002). A correlação espacial entre a distribuição da argila e os teores de alumínio no solo foi avaliada pela construção de semivariogramas cruzados, também pelo software Variowin. Para estes, o escalonamento utilizado foi a covariância das variáveis analisadas.

\section{Resultados e Discussão}

A análise descritiva dos dados referentes aos teores de argila e alumínio (Tabela 1) demonstrou a normalidade na distribuição dos dados. Também pôdese reportar a simetria dos mesmos, principalmente pela análise de valores próximos de média e mediana, e dos valores referentes à assimetria, que estiveram próximos de zero. O desvio padrão das variáveis argila e saturação por alumínio, analisados em dados da camada superficial do solo, apresentou-se médio $(25,7 \%-22,4 \%)$. 
Tabela 1. Estatística descritiva para as variáveis argila e alumínio

\begin{tabular}{llc}
\hline Parâmetros & Argila & Saturação de Alumínio \\
\hline $\mathrm{N}^{\circ}$ amostras & 77 & 77 \\
Média & $39,66^{1}$ & $48,61^{2}$ \\
Mediana & $39,00^{1}$ & $52,63^{2}$ \\
Mínimo & $2,00^{1}$ & $0,00^{2}$ \\
Máximo & $84,00^{1}$ & $93,61^{2}$ \\
Quartil superior & $19,00^{1}$ & $37,08^{2}$ \\
Quartil inferior & $58,00^{1}$ & $64,17^{2}$ \\
Desvio padrão & $25,70^{1}$ & $22,45^{2}$ \\
Variância & 660,98 & 503,91 \\
Assimetria & 0,09 & $-0,50$ \\
\hline
\end{tabular}

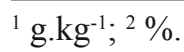

A simetria apresentada pela distribuição das variáveis em questão pode ser comprovada por meio da observação dos gráficos de "P-Plot" (Figura 2).
Nestes, a argila se caracteriza pela distribuição mais uniforme do que o alumínio.

Figura 2. Gráficos "P-Plots" demonstrando a simetria de distribuição das variáveis.
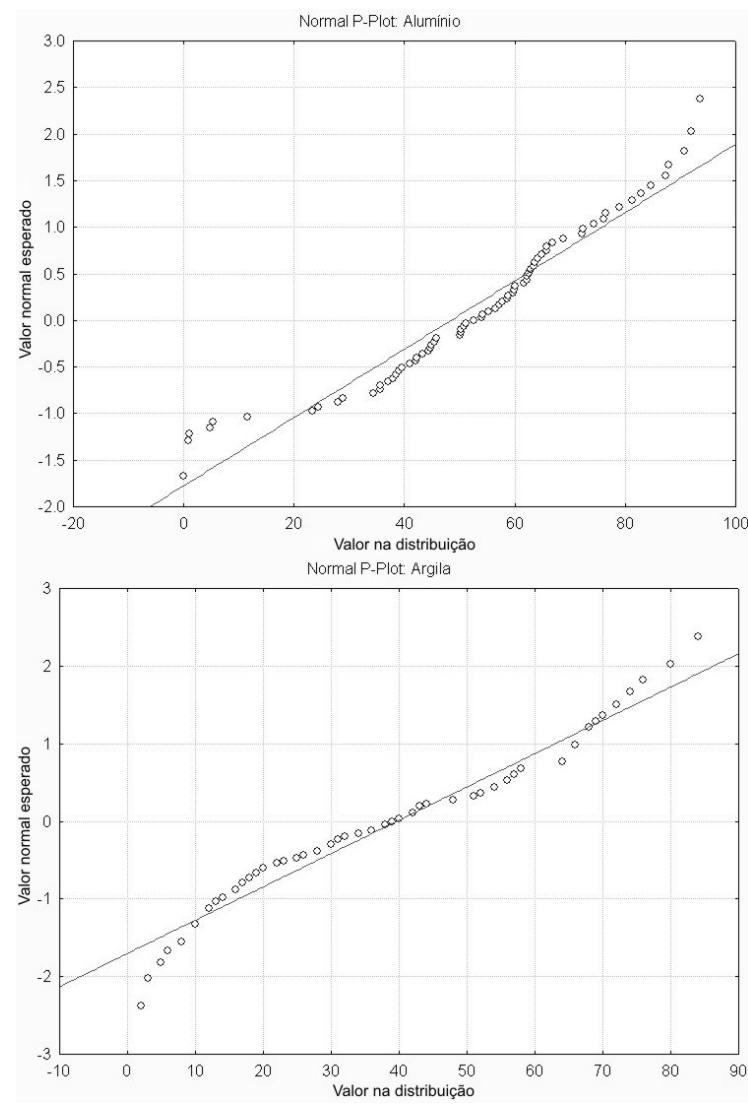
Com as inferências advindas dos testes preliminares sobre a distribuição dos dados e suas condições favoráveis quanto à normalidade e simetria, a elaboração dos semivariogramas foi o passo seguinte, onde se caracterizou a presença de dependência espacial para ambas as variáveis, assim como observado por Vieira, Nielsen e Biggar (1981).

Devido à grande área abrangida pela grade de pontos amostrais, foram obtidos pelos semivariogramas valores de dependência espacial elevados, caracterizando relativa homogeneidade na área de estudo quanto a esses elementos
(CHICATI et al., 2008), o que concorda com as observações de Vieira, Nielsen e Biggar (1981); Vieira et al. (1983); Trangmar, Yost e Uehara (1985), Souza, Cogo e Vieira (1999); Salviano, Vieira e Sparovek (1998); Oliveira et al. (1999) e Berg e Oliveira (2000). Com a seleção de seis semivariogramas por validação cruzada, procedeu-se ao escalonamento pela variância das amostras, obtendo-se um semivariograma ajustado pelo modelo esférico para a variável 'argila', e outro ajustado pelo modelo gaussiano para a variável ‘alumínio’ (Figura 3).

Figura 3. Semivariogramas escalonados para as variáveis argila (Pepita: 220; Alcance: 4644) e alumínio (Pepita: 482; Alcance: 2475).
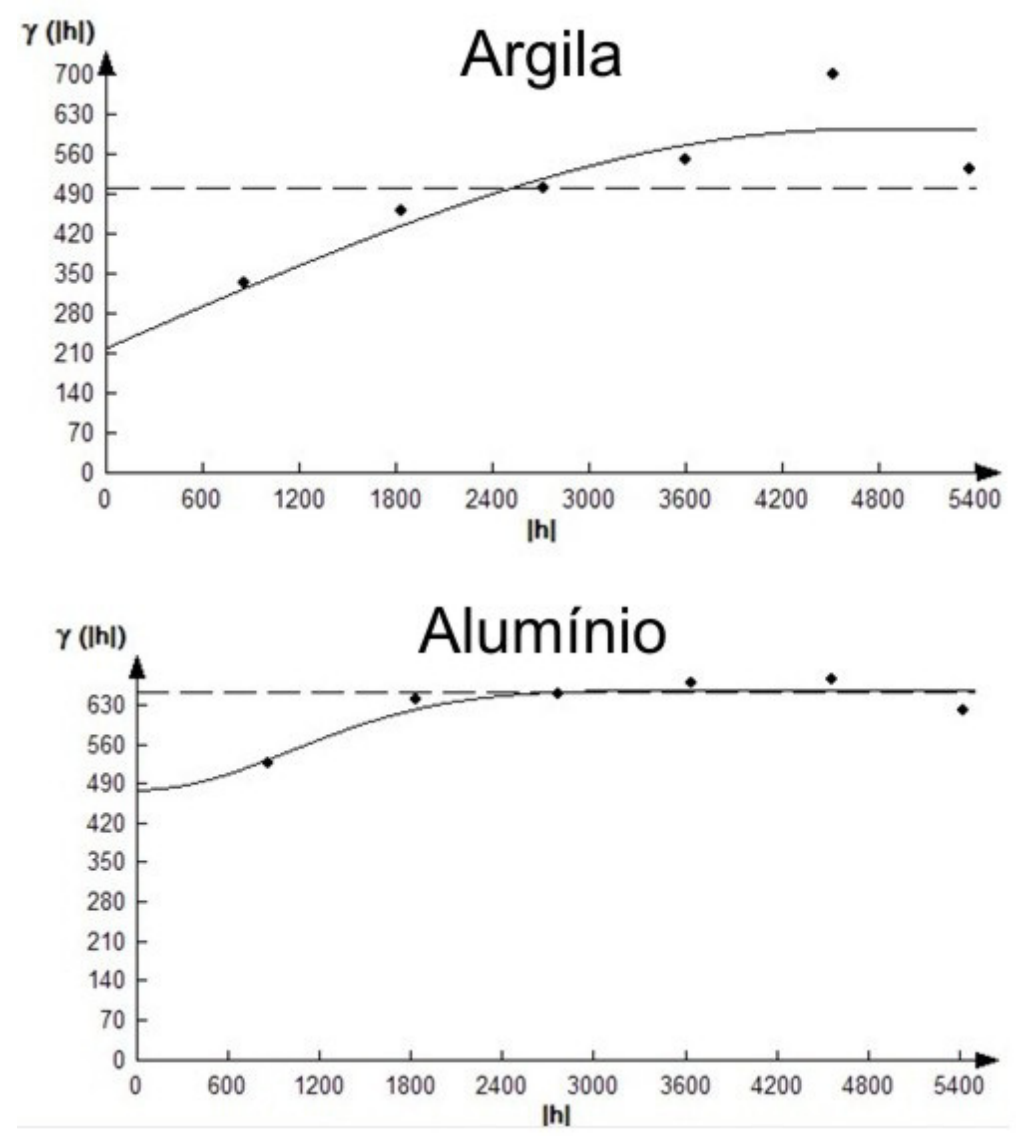
O semivariograma cruzado (Figura 4) que dispôs a relação entre as variáveis, mostrou um resultado melhor ajustado ao modelo gaussiano e apresentou dependência espacial entre o teor de alumínio e a argila até um alcance de $1600 \mathrm{~m}$, caso esse que se deve também ao fator extensão empregado na delimitação da grade de amostragem dos solos. Essa observação confirmou que a dependência espacial na distribuição granulométrica dos solos, na região de estudo, apresenta semelhança real sobre os níveis de alumínio determinados nas análises, corroborando a relação entre elementos apresentada por Foy et al. (1965).

Figura 4. Semivariograma cruzado demonstrando a relação da distribuição espacial de Argila (eixo X) e Alumínio (eixo Y) (Alcance: 1600).

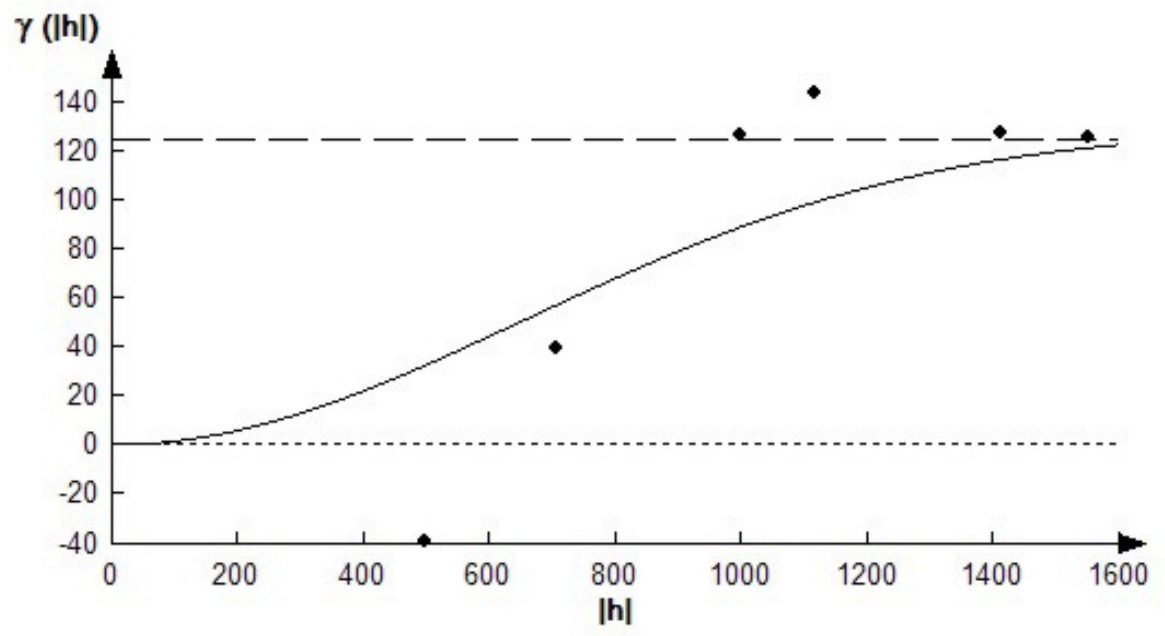

Os mapas tridimensionais produzidos (Figura 5) demonstram que há um comportamento semelhante entre a amplitude ao redor da média, tanto para a argila como para o alumínio em relação à distribuição dos dois na região amostrada. $\mathrm{Na}$ prática, essa relação pode ser visualizada nos pontos mais críticos apresentados pelos mapas, isto é, onde predominam os solos mais argilosos mostrando assim que, a dependência entre as variáveis condiciona-se não só pela distância, mas também pela direção dos pontos amostrados.

Onde o alumínio visualmente apresentou teores mais altos (Figura 5), houve correspondência com a mudança textural do solo, predominando as classes de solo mais arenosas e consideradas menos atrativas ao cultivo agrícola e também aquelas comumente mais afetadas pelos efeitos antagônicos provocados por esse elemento, como relatados por Sousa e Lobato (2004). Os pontos amostrais demonstrando altos teores de alumínio foram apresentados pelos mapas correspondendo às regiões com variabilidade aleatória mais acentuada das médias relativas, fato que comprovaria os referenciais da estatística clássica, conforme Trangmar, Yost e Uehara (1985), Fietz (1998) e Gonçalves (1997), ou seja, que estas vem a ocorrer nas regiões mais extremas e distantes da origem dos dados no semivariograma. 
Figura 5. Distribuição tridimensional do comportamento das variáveis argila e alumínio na área amostral.
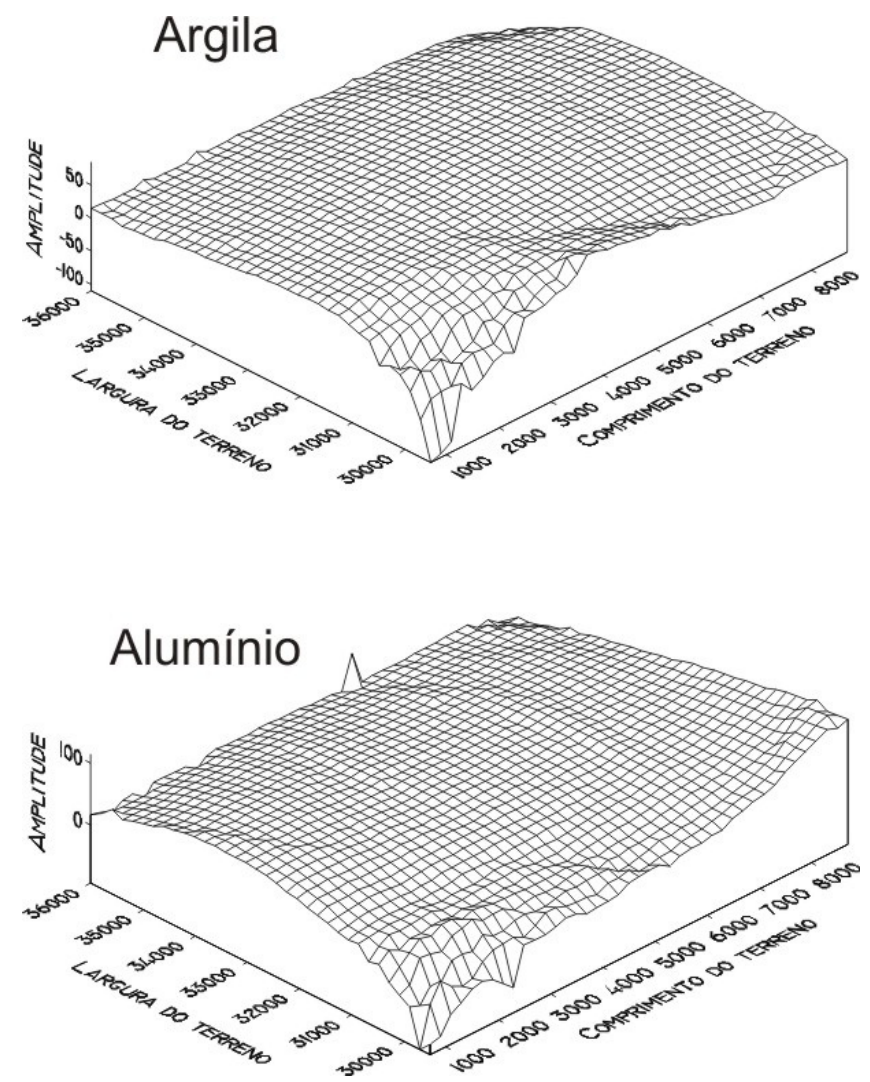

\section{Conclusões}

Os teores de argila e de alumínio nos solos estudados apresentam estrutura de dependência espacial;

Há uma correlação positiva entre o conteúdo de argila no solo e o teor de alumínio nele presente, sendo esta comprovada espacialmente.

\section{Agradecimentos}

Ao Conselho Nacional de Desenvolvimento Científico e Tecnológico, pela concessão de bolsa ao primeiro autor (Proc. n. 134501/2004-7) e ao segundo autor (Proc. n.310948/2006-1) e à CAPES pela concessão de bolsa ao terceiro autor.

\section{Referências}

BARBER, S. A. Soil nutrient bioavailability: a mechanistic approach. 2. ed. New York: John Wiley \& Sons, $1995.414 \mathrm{p}$.

BERG, M. van den; OLIVEIRA, J. B. Variability of apparently homogeneous soilscapes in São Paulo Stade, Brazil. II. Quality of soil maps. Revista Brasileira de Ciência do Solo, Viçosa, v. 1, n. 24, p. 393-407, 2000.

CÂMARA, G.; MEDEIROS, J. S. Mapas e suas representações computacionais. In: ASSAD, E. D.; SANO. E. E. Sistemas de Informações geográficas aplicações na agricultura. Brasília : Embrapa/SPI, 1998. cap. 2, p. 13-29.

CHICATI, M. L.; NANNI, M. R.; CÉZAR, E.; DEMATTÊ, J. A. M.; OLIVEIRA, R. B. Caracterização de alguns atributos do solo e sua correlação com a paisagem em uma porção do noroeste do Estado do Paraná. Acta Scientiarum Agronomy, Maringá, v. 30, p. 719-724, 2008. Suplemento.

EMPRESA BRASILEIRA DE PESQUISA AGROPECUÁRIA - EMBRAPA SNLCS. Normas 
e critérios para levantamentos pedológicos. Rio de Janeiro: Ministério da Agricultura e do Abastecimento, 1996. $94 \mathrm{p}$.

- Manual de métodos de análises de solo. 2. ed. Rio de Janeiro: Ministério da Agricultura e do Abastecimento, 1997. 212 p.

. Sistema brasileiro de classificação de solos. 2. ed. Rio de Janeiro: EMBRAPA- CNPS, 2006. 306 p.

FIETZ, C. R. Variabilidade espacial do armazenamento de água no solo visando o manejo da irrigação por aspersão. 1998. Tese (Doutorado em Irrigação) - Escola Superior de Agricultura Luiz de Queiroz. ESALQ/USP, Piracicaba.

FOY, C. D.; BURNS, G. R.; BROWN, J. C.; FLEMING, A. L. Differential aluminum tolerance of two wheat varieties associated with plant-induced ph changes around their roots. Soil Science Society of America Journal, Madison, v. 29, n. 1, p. 64-67, 1965.

GOLDEN SOFTWARE. Surfer for windows - User's guide Release 8.0. USA, 2002. 340 p.

GONÇALVES, A. C. A. Variabilidade espacial de atributos fisicos do solo e resposta espectral da cultura de feijão irrigado, em imagens aéreas digitais. 1997. Tese (Doutorado em Engenharia Agrícola)- Escola Superior de Agricultura Luiz de Queiroz. ESALQ/USP, Piracicaba.

INSTITUTO NACIONAL DE PESQUISAS ESPACIAIS - INPE. Manuais do sistema de processamento de informações georreferenciadas (SPRING). São José dos Campos: INPE. 2004.

LIBARDI, P. L.; MANFRON, P. A.; MORAES, S. O. de; TUON, R. L. Variabilidade da umidade gravimétrica de um solo hidromórfico. Revista Brasileira de Ciência do Solo, Viçosa, v. 20, n. 1, p. 1-12, 1996.

MCBRATNEY,A. B.; WEBSTER, R. Choosing functions for semi-variograms of soil properties and fitting them to sampling estimates. Journal of Soil Science, Oxford, v. 37, n. 4, p. 617-639, 1986.

OLIVEIRA, J. J.; CHAVES, L. H. G.; QUEIROZ, J. E.; LUNA, J. G. Variabilidade espacial de propriedades químicas em um solo salino-sódico. Revista Brasileira de Ciência do Solo, Viçosa, v. 23, n. 1, p. 783-789, 1999.

PANNATIER, Y. Variowin: software for spatial data analysis in 2D. New York: Springer-Verlag, 1996. 90 p.

PANOSSO, A. R.; RIBEIRO, C. E. R.; ZANINI, J. R.; PAVANI, L. C.; PEREIRA, G. T.; LA SCALA JÚNIOR, N. Variabilidade espacial da emissão de CO2, da temperatura e umidade de um latossolo desprovido de vegetação sob diferentes lâminas de molhamento. Semina: Ciências Agrárias, Londrina, v. 30, p. $1017-$ 1034, 2009. Suplemento 1.

SALET, R. L.; ANGHINONO, I.; KOCHHANN, R. A. Atividade do alumínio na solução de solo do sistema plantio direto. Revista Cientifica Unicruz, Cruz Alta, v. 1, n. 1, p. 9-13, 1999.

SALVIANO, A. A. C.; VIEIRA, S. R.; SPAROVEK, G. Variabilidade espacial de atributos de solo e de Crotalaria juncea-L em área severamente erodida. Revista Brasileira de Ciência do Solo, Viçosa, v. 22, n. 1, p. 115-122, 1998.

SOUSA, D. M. G.; LOBATO, E. Adubação com nitrogênio. In: SOUSA, D. M. G.; LOBATO, E. (Ed.). Cerrado: correção do solo e adubação. 2. ed. Planaltina: Embrapa Cerrados, 2004. p. 129-144.

SOUZA, L. S.; COGO, N. P.; VIEIRA, S. R. Variabilidade espacial de fatores de acidez no solo, em diferentes sistemas de manejo. Pesq. Agropec. Gaúcha, Porto Alegre, v. 5, n. 1, p. 83-98, 1999.

STATSOFT. Statistica, version 6.0. Statsoft Company. 1996.

TRANGMAR, B. B.; YOST, R. S.; UEHARA, G. Application of geostatistics to spatial studies of soil properties. Advances in Agronomy, New York, v. 38, n. 1, p. 45-93, 1985.

VIEIRA, S. R.; HATFIELD, J. L.; NIELSEN, D. R.; BIGGAR, J. M. Geostatistical theory and application to variability of some a agronomical properties. Hilgardia, Berkeley, v. 51, n. 3, p. 1-75, 1983.

VIEIRA, S. R.; NIELSEN, D. R.; BIGGAR, J. W. Spatial variability of field-measured infiltration rate. Soil Science Society of America Journal, Madison, v. 45, n. 6, p. 10401048, 1981. 
